\title{
Integrated Approach for the Intensification of Heterogeneous Catalytic Processes
}

\author{
Lioubov Kiwi-Minsker* and Micaela Crespo-Quesada
}

\begin{abstract}
The integrated approach for the design of solid catalysts for process intensification is presented addressing simultaneously different levels of scale and complexity involved in the development starting from the molecular/nano-scale of the active phase optimization up to the macro-scale of the catalytic reactor design. The feasibility of this approach is demonstrated through case studies carried out in our group.
\end{abstract}

Keywords: Metal nanocrystals · Selective hydrogenation $\cdot$ Structured catalyst $\cdot$ Structure sensitivity

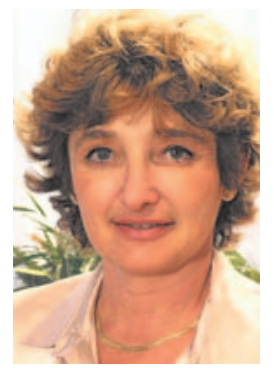

\section{Introduction}

Process intensification is a vibrant topic in the field of chemical engineering which has attracted a lot of attention during the past few decades. It aims at the development of novel equipment, processing techniques, and operational methods to increase the efficiency of chemical plants and markedly shrinking their size making the process cleaner, safer and less energy-consuming. ${ }^{[1]}$

Catalysis is a key technology for the economical and environmentally benign chemical transformation of raw materials into useful products. Heterogeneous catalytic reactions account for over $85 \%$ of the industrial chemical processes and about 2 billion dollars in sales. In order to strengthen the competitiveness of chemical industries in Europe, a revitalization of the research on catalytic technologies and materials has been observed during the last decade. ${ }^{[2-4]}$ Catalysts allow the desired products to be obtained with high selectivity, thus minimizing the material and energy loss and respecting the sustainability of their production.
${ }^{\star}$ Correspondence: Prof. Dr. L. Kiwi-Minsker Group of Catalytic Reaction Engineering Ecole Polytechnique Fédérale de Lausanne Station 6

$\mathrm{CH}-1015$ Lausanne

Tel.: +41216933182

Fax: +41216933190

E-mail: lioubov.kiwi-minsker@epfl.ch
To fully exploit the high intrinsic activity and selectivity of a catalyst, the chemical reactor has to be designed and operated optimally, that is, any mass and heat transfer resistances must be minimized, and the residence or contact time of the reactants in the reactor must be well defined. The conditions within the reactor must be controllable at any location and at any time since the best reactor performance and highest product selectivity can only be ensured when the optimal reaction conditions are maintained throughout the reactor.

In addition to the design of the reactor, the design of the shape and texture of solid catalysts is crucial to achieve the full benefits of a catalytic process. In conventional fixed-bed reactors, catalyst particles of various sizes are often randomly distributed, which may lead to inhomogeneous flow patterns. Near the reactor walls the packing density is lower, making faster flow of the fluid near the wall unavoidable. As a result, reactants may bypass the catalyst particles, and the residence time distribution (RTD) will be broadened. Moreover, the non uniform access of reactants to the catalytic surface diminishes the overall reactor performance and can lead to unexpected hot spots and even to reactor runaway in the case of exothermic reactions. Furthermore, pressure drop in randomly packed beds, i.e. energy consumption, is a crucial matter in process economics, in particular when large quantities of raw materials have to be converted. On the other hand, when reactions are conducted in suspensions such as in fluidized beds or slurry reactors, pressure drop is minimized, but catalyst abrasion and catalyst recovery become critical issues.

To overcome the drawbacks of conventional catalytic reactors, structured catalysts and reactors may be used. ${ }^{[5,6]}$ Well-known examples are monolithic converters, catalyst-coated static mixers, and arranged packing as applied in distillation and absorption columns. Further examples are catalytic grids, woven fabrics, felts, and foams. ${ }^{[7]}$ Structured catalysts are characterized by high porosities, in the range of $0.7-0.9$, relative to packed beds with porosities of typically 0.5 . The pressure drop in a structured packing is 2-4 times lower than in conventional fixed beds. The open cross-flow structure of arranged catalysts facilitates intensive radial mixing and leads to narrow RTDs in tubular reactors.

In summary, in order to attain the intensification of catalytic processes, an integrated approach has to be applied conjugating catalyst and reactor design over multiple levels as presented in Fig. 1: i) molecular and nano-scale of the optimal active center; ii) meso-scale of the catalytic active phase and the support nature; iii) micro-scale of the support structure including its microporosity; iv) milli-scale of the finished catalyst with its 3D structure; v) macro-scale of the catalytic bed within a reactor.

This approach requires a combination of interdisciplinary competences of chemical reactor and catalytic engineering, synthetic chemistry and surface science, as well as physics and modeling.

The following sections present selected examples based on the work from our group illustrating an integrated approach for intensifying a catalytic process spanning from molecular to reactor scale level. The industrially important selective semihydrogenation of 2-methyl-3-butyn-2-ol (MBY) over Pd-based structured catalysts was used as a model reaction.

\section{Molecular/Nano-scale Level of Active Site Design}

Heterogeneous catalysis involves an active site (molecular scale) in chemical transformation via rupture and creation of bonds within the coordination sphere. 


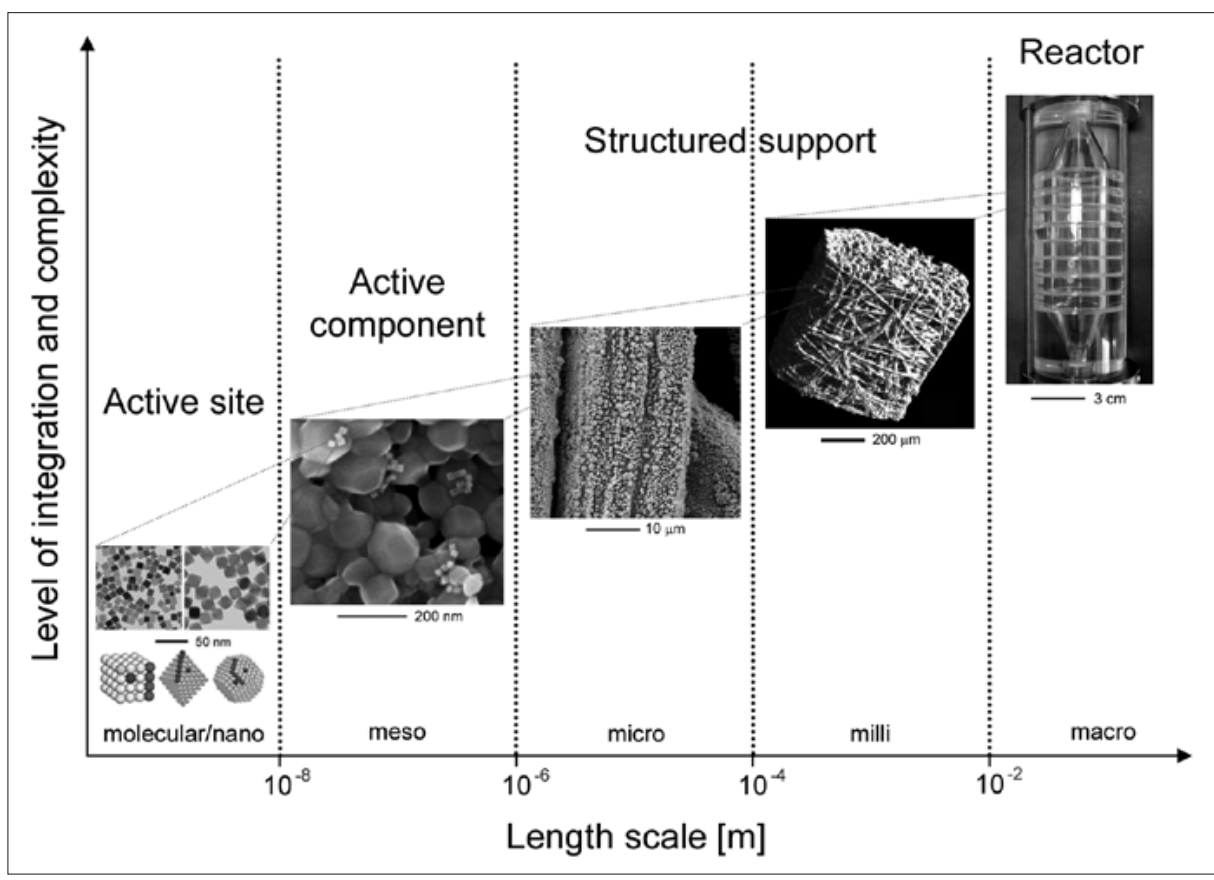

Fig. 1. Levels of scale and complexity for catalytic process development.

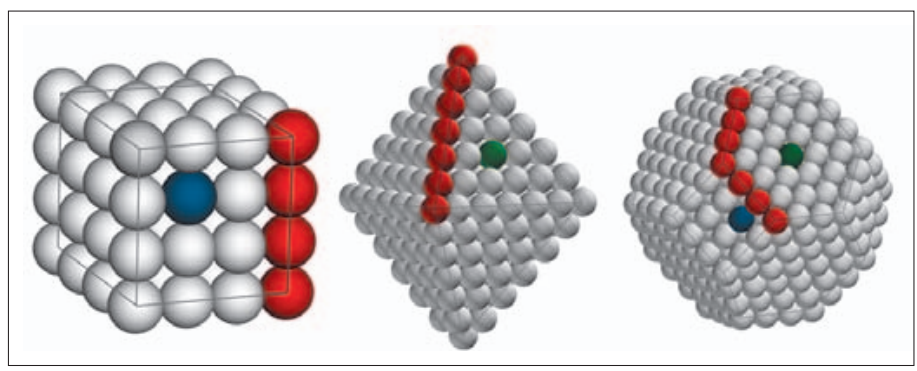

Fig. 2. Three common shapes $\mathrm{Pd}$ nanocrystals: $\bullet \mathrm{Pd}_{(111)}$ - $\mathrm{Pd}_{(100)}$ and - Edge and vertex atoms.

However, contrary to homogeneous catalysis by metal complexes, in solid catalysts active sites are present on the surface of nanocrystals and are, therefore, inherently heterogeneous (e.g. vertex, edge, and plane atoms, see example in Fig. 2). Therefore, if different surface atoms possess different catalytic activity and/or selectivity, then the response will depend on nanoparticle (NPs) morphology resulting in the so called structure-sensitivity of catalytic reactions. A relevant example of this type of reactions is the selective hydrogenation of triple bonds of unsaturated hydrocarbons catalyzed by Pd NPs. ${ }^{[8]}$

The fraction of atoms located on (111) and/or (100) crystallographic planes increases with size at the expense of edge and vertex atoms. This change leads to a size effect, which manifests itself with an increase (antipathetic structure-sensitivity) or decrease (sympathetic structure-sensitivity) of the turnover frequency (TOF) as a function of particle size. In addition, shape variation of Pd NPs can result in important morphological differences: for example, Pd cubes only display (100) plane atoms on the surface while Pd octahedra only present (111) plane atoms and cubooctahedra have a mixture of both. This difference contributes to a shape effect, and size effects could be used to perform a rational design of the catalytic active

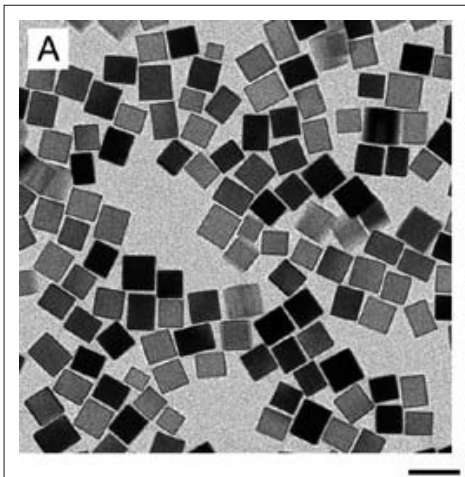

phase on a nano-level to achieve a superior activity and/or selectivity.

To gain a fundamental understanding of structure-sensitivity of triple bond hydrogenations, ${ }^{[8]}$ three different shapes of $\mathrm{Pd}$ NPs have been synthesized, namely cubes, octahedra and cubo-octahedra of different sizes through a solution-phase method with poly (vinyl pyrrolidone) (PVP) serving as stabilizer. After the synthesis, Pd NPs were cleaned up from the stabilizing agents and tested per se (in unsupported form) in the water-assisted hydrogenation of 2-methyl3-butyn-2-ol (MBY) in order to compare the activity and selectivity of plane surface atoms, namely $\mathrm{Pd}_{(100)}$ and $\mathrm{Pd}_{(111)}$, with that of edge surface atoms, $\mathrm{Pd}_{\text {edge }}$. Specifically, we examined Pd nanocubes of two different sizes ( $6 \mathrm{~nm}$ and $18 \mathrm{~nm}$ in edge length), $\mathrm{Pd}$ octahedra of $31 \mathrm{~nm}$ in edge length, and $\mathrm{Pd}$ cubo-octahedra of $5.5 \mathrm{~nm}$ in size. Figs 3A, B show TEM images of the Pd nano-cubes (CUB 18), Pd nano-octehedra (OCT), with $18 \mathrm{~nm}$ and $31 \mathrm{~nm}$ edge lengths, respectively. HRTEM imaging of each sample showed the nanocrystals to be monocrystalline and bounded by the expected crystallographic planes as seen in Figs 3C, D.

The statistics of surface atoms ${ }^{[9]}$ for ideal face-centered cubic $(f c c)$ nanocrystals allow one to determine the relative numbers of different types of surface atoms on a nanocrystal with a given size and shape.

The reaction network for 2-methyl3-butyn-2-ol (MBY) hydrogenation is depicted in Scheme 1. Two types of sites are assumed to be involved in the catalysis: $\sigma_{1}-$ plane $\mathrm{Pd}$ atoms; $\sigma_{2}-$ edge $\mathrm{Pd}$ atoms. MBY can be either semi-hydrogenated to
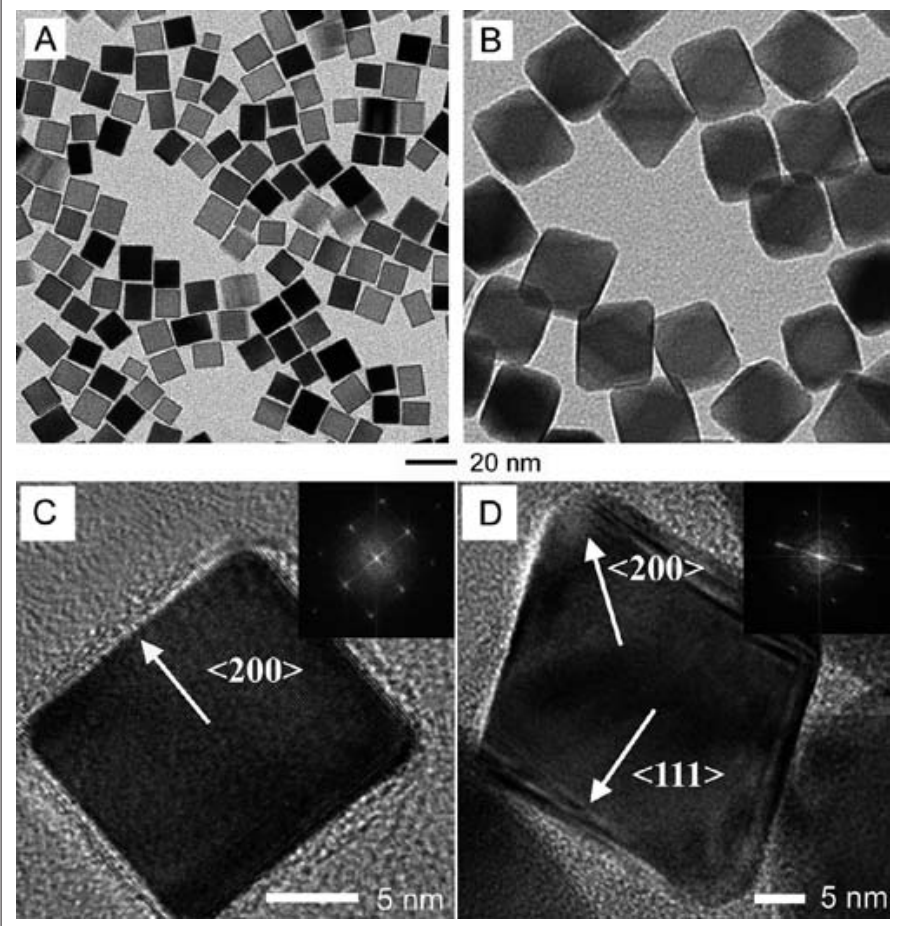

Fig. 3. TEM and HRTEM images of the PVP-stabilized Pd nanocrystals used in this work. $A$ and C) 18 $n m$ cubes and $B$ and D) $31 \mathrm{~nm}$ octahedra. The inset in panels $C$ and $D$ show the FTT patterns of an individual nanoparticle where the lattice spacings can be indexed to reflections of facecentered cubic $\mathrm{Pd}$ as depicted in each panel. 


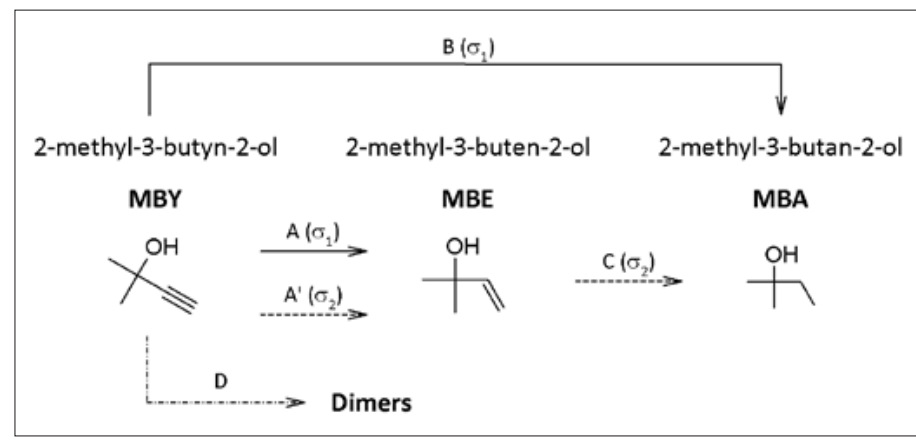

Scheme 1.

Table 1. Activity ${ }^{a}$ model applied to the catalytic responses of differently shaped Pd nanocrystals to account for the structure sensitivity of the reaction.

$\begin{array}{lllll}\text { Sample } & \begin{array}{l}-\mathrm{R}_{\mathrm{MBY}} \\ {\left[\mathrm{mol} \times \mathrm{mol}_{\mathrm{Pd}}{ }^{-1} \times \mathrm{s}^{-1}\right]}\end{array} & \begin{array}{l}\mathrm{TOF}_{\text {obs }} \\ {\left[\mathrm{s}^{-1}\right]}\end{array} & \begin{array}{l}\mathrm{TOF}_{\text {plane }} \\ {\left[\mathrm{s}^{-1}\right]}\end{array} & \begin{array}{l}\mathrm{TOF}_{\text {edge }} \\ {\left[\mathrm{s}^{-1}\right]}\end{array} \\ \text { CUB6 } & 2.55 & 15.3 & & \\ \text { CUB18 } & 1.05 & 17.5 & & \\ \text { OCT } & 0.53 & 14.6 & 19.3 \pm 2.4 & 4.7 \pm 0.8 \\ \text { COT } & 2.25 & 12.3 & & \end{array}$

aReaction conditions: $1 \mathrm{~g}$ of MBY, MBY: $\mathrm{Pd}_{\text {surf }}=140000,200 \mathrm{~mL}$ of $\mathrm{H}_{2} \mathrm{O}, 60^{\circ} \mathrm{C}, 0.3 \mathrm{MPa}$ of $\mathrm{H}_{2}$.
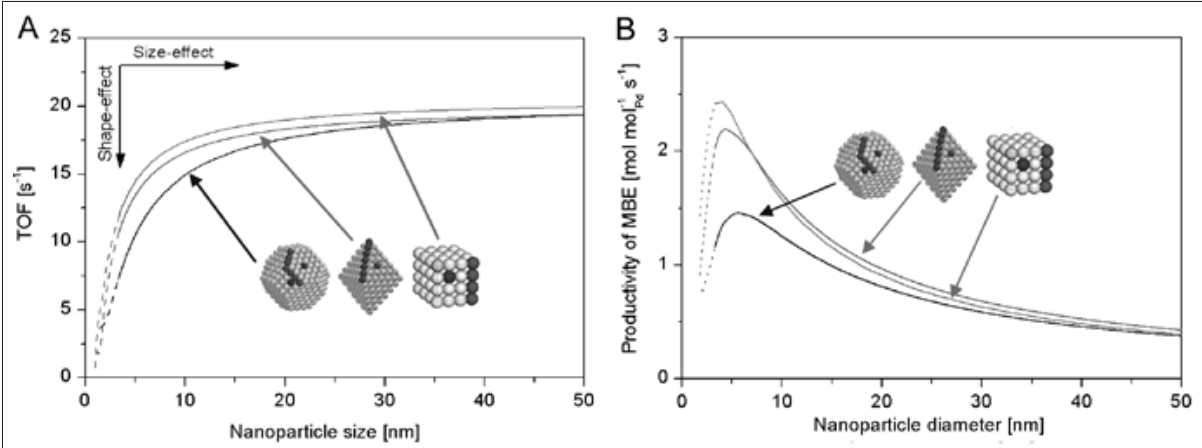

Fig. 4. Optimization of Pd nanocrystal size and shape based on MBE productivity TOF (A) and total $\mathrm{Pd}(\mathrm{B})$.

2-methyl-3-buten-2-ol (MBE) over both types of sites (path $A, A^{\prime}$ ), directly hydrogenated to 2-methyl-3-butan-2-ol (MBA) over sites $\sigma_{l}$, (path $B$ ) or MBE can be over-hydrogenated in consecutive reaction (path $C$ ) to MBA over sites $\sigma_{2}$. In this work oligomerization (path $D$ ) was not observed, and thus, was eliminated from the network for simplicity.

Comparing activity of cubes with octahedral of different sizes led to the conclusion that $\mathrm{Pd}_{(100)}$ and $\mathrm{Pd}_{(111)}$ plane atoms have a similar activity. Therefore, the following model was suggested to describe catalytic activity:

$$
T O F_{o b s}=T O F_{\sigma_{1}} \cdot x_{\sigma_{1}}+\mathrm{TOF}_{\sigma_{2}} \cdot x_{\sigma_{2}}
$$

The application of the model (see Table 1) simultaneously to all four samples allowed the estimation of the specific plane and edge TOFs, which were found to be $19.3 \pm 2.4 \mathrm{~s}^{-1}$ and $4.7 \pm 0.8 \mathrm{~s}^{-1}$, respectively. This result suggests that MBY adsorbs on all types of surface atoms, but its reactivity depends on the coordination number of the active site.

The TOF data obtained can be combined with the statistics of surface for common nanocrystal shapes to yield the graphs presented in Fig. 4A and B.

As expected, shape does not exert a considerable effect on TOF for MBY transformation since both (111) and (100) planes behave similarly. Cubo-octahedra, however, are slightly disfavored due to the larger fraction of edge atoms (or $\sigma_{2}$ sites), which are considerably less active in the hydrogenation of MBY relative to plane atoms (or $\sigma_{1}$ sites). The most significant size effect is observed in the $3-20 \mathrm{~nm}$ range, after which the reaction becomes size and shape independent with respect to TOF. Nanocrystals smaller than $3 \mathrm{~nm}$ in size start to lose their bulk properties ${ }^{[10,11]}$ and, consequently, the catalytic behavior may not follow the prediction. This region is depicted with dotted lines.

If, on the other hand, MBE productivity is used as optimization criterion, then both size and shape effects change substantially (Fig. 4B). While there would be no difference between cubic or octahedral nanocrystals, cubo-octahedra will be significantly less active due to their lower dispersions. Therefore, if the productivity of MBE is to be maximized, then cubic nanocrystals of approximately $3 \mathrm{~nm}$ would be the best choice.

The structure-sensitivity of a chemical reaction is specific for each catalytic system. Therefore, such a modeling-simulation approach combined with the experimental kinetic data obtained from uniform, well-defined metal nanocrystals, gives a powerful tool for the rational design of catalytic active phases for a given chemical reaction. To the best of our knowledge, this is the first attempt to experimentally determine a catalytic action of different $\mathrm{Pd}$ surface sites by using model crystal nanoparticles and to apply for an active particles optimization.

\section{Meso/Micro-scale Level of Catalyst Design}

During the long process of catalyst development the identification of a catalytically active phase is the first but not the last step, which is usually followed by the choice of a suitable support. It is well known that the environment around the active site plays an important role influencing its activity, selectivity and stability, although often not enough care is given to this aspect. The optimal support is often based on the catalyst screening in the form of powders, which properties can be changed after catalyst's shaping as pellets, monoliths or any other form.

Our approach is based on a deposition of the pre-optimized nano-sized catalytically active phase on micro-structured materials with tuned surface properties (acidity/basicity) as well as its morphology and micro/meso-porosity. The goal is to achieve an optimal spatial distribution of active nano-particles together with its strong anchoring to the support surface.

Herein we report as an example the development of an active/selective structured catalyst for the hydrogenation of an acetylenic alcohol (MBY) in aqueous media and represents a valuable alternative to the commercial Lindlar's catalyst (powder of $\mathrm{Pd}, \mathrm{Pb} / \mathrm{CaCO}$ ). The latter is known to be unsuitable for hydrogenations in aqueous media due to irreversible deactivation caused by support hydroxylation.

Three-dimensional sintered metal fibers (SMF) were chosen in this work as a structured support for the deposition of Pd NPs (mean diameter of 6-7 nm, synthesized beforehand) as the active phase. The SMF filters have high permeability, mechanical strength and high thermal conductivity being advantageous for exother- 
mic hydrogenations. The SMF surface was coated by $\mathrm{ZnO}$ since for MBY hydrogenation selectivity to MBE has been found to increase in the following order: Pd black $<$ $\mathrm{Pd} / \mathrm{C}<\mathrm{Pd} / \mathrm{Al}_{2} \mathrm{O}_{3}<\mathrm{Pd} / \mathrm{BaSO}_{4}<\mathrm{Pd} / \mathrm{MgO}<$ $\mathrm{Pd} / \mathrm{ZnO} \cong \mathrm{Pd} / \mathrm{CaCO}_{3} \cdot{ }^{[12]}$

Rational synthetic procedure ${ }^{[13,14]}$ applied to the SMF coating led to the active/ selective catalytic phase of $\mathrm{Pd} / \mathrm{PdZn} / \mathrm{ZnO}$ (Fig. 5) with improved stability in aqueous media as compared to the commercial Lindlar's catalyst. The catalyst was tested in a semibatch reactor and the results are shown in Fig. 6.

The catalyst exhibited one order of magnitude higher activity compared to the commercial Lindlar catalyst and provided $95.3 \%$ yield of MBE at $308 \mathrm{~K}, 5$ bar. The consecutive MBE hydrogenation to the saturated alcohol was suppressed. The structured catalyst could be reused after ultrasonic regeneration contrary to Lindlar's catalyst which deactivates completely in aqueous reaction media during the first run. Therefore, the $\mathrm{Pd} / \mathrm{ZnO} / \mathrm{SMF}$ catalyst has been shown as suitable for continuously operation and could be incorporated in a Staged Bubble Column Reactor (SBCR).

\section{Milli/Macro-scale Level of Reactor Design}

Milli/macro-scale of catalyst design is closely linked with the reactor design and refers to the macro-structured material conjugated with the development of a complex devise (such as a reactor with integrated heat exchanger and mixers, etc.) aimed at process intensification via improved multiphase contact and heat transfer management.

Below we report the example using the same model reaction of MBY hydrogenation over a structured Pd-based catalyst. ${ }^{[15]}$ A novel reactor based on a bubble column staged by structured catalytic layers of $\mathrm{Pd} /$ $\mathrm{ZnO} / \mathrm{SMF}$ with integrated cross flow micro-heat-exchangers (HEX) was designed and tested. As the diameter of a single fiber in SMF material is in the micrometer range, internal and external liquid/solid mass-transfer limitations can be effectively avoided, while the open macrostructure of the SMF material gives a low pressure drop during the passage of fluids. It also helps for micro-mixing and enhances bubble redistribution on each stage. Due to the variable distance between catalyst layers, staged bubble column reactors can be easily adjusted to process requirements in catalyst loading, reactor volume and phase mixing intensity. Therefore, integrated heat exchange (HEX) elements were designed to be placed between adjacent catalyst layers within the bubble column, forming an integral unit of a reactor stage. Thus, reac-

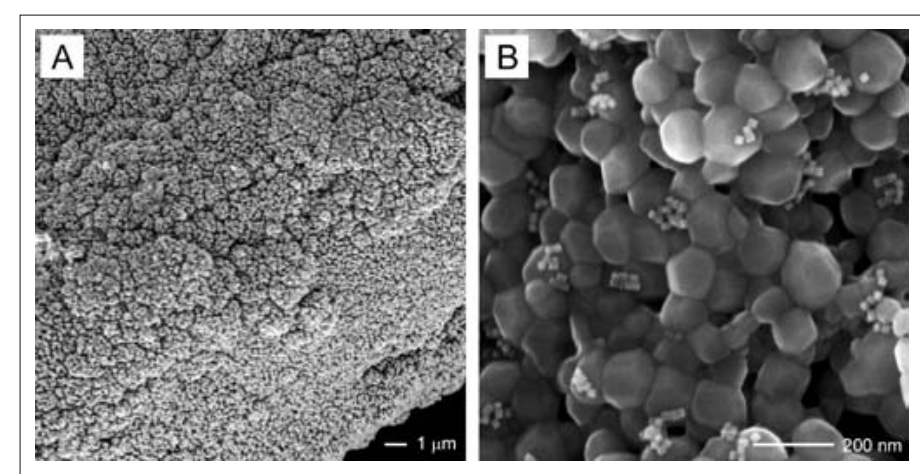

Fig. 5. High

resolution SEM images at different magnifications of Pdcubes supported on SMF coated by $\mathrm{ZnO}$ grains.

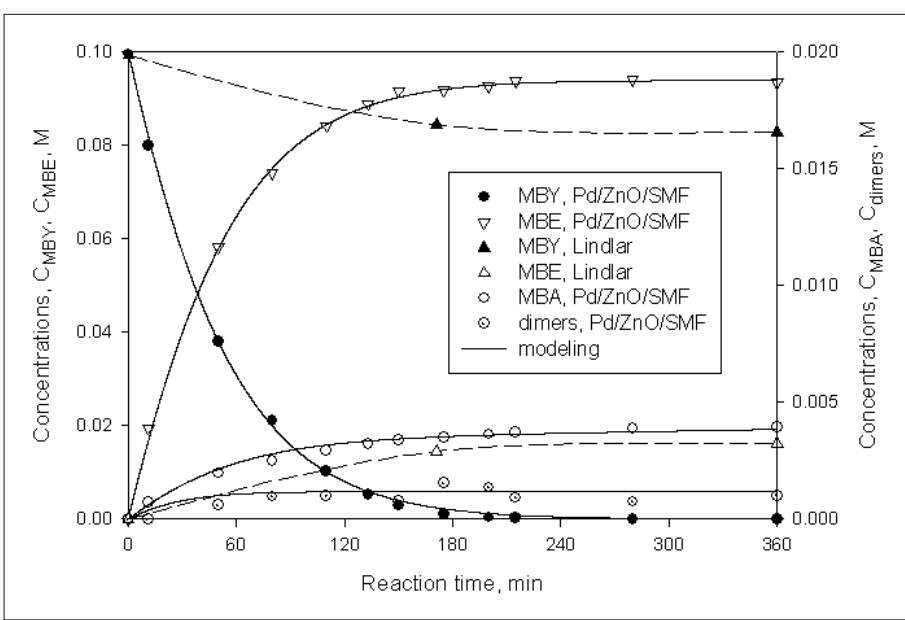

Fig. 6. Concentrations of MBY and products vs. reaction time during hydrogenation over 0.2 wt. \% Pd / 6 wt. \% ZnO / SMF catalyst in water as solvent.

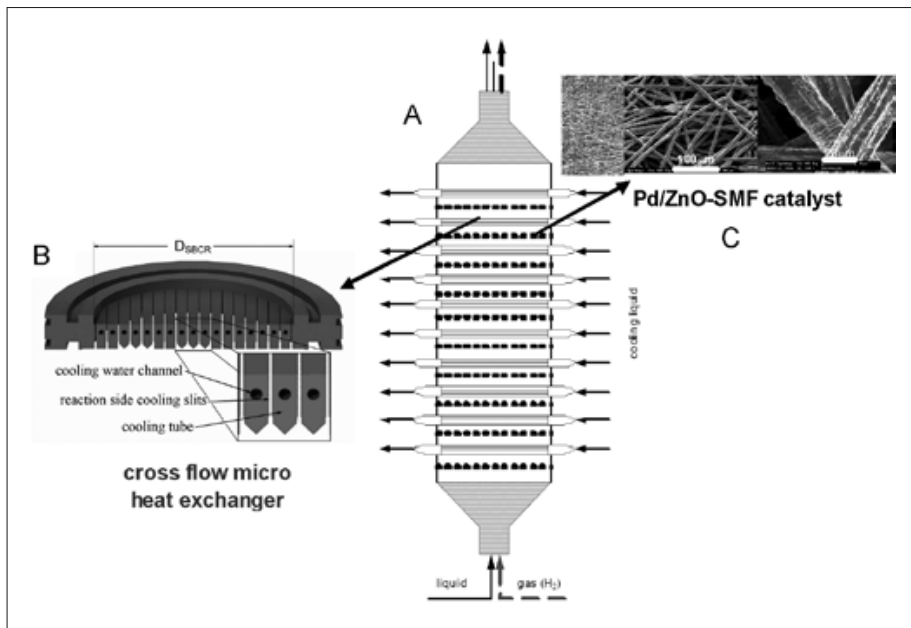

Fig. 7. A) Staged bubble column reactor with integrated catalyst layers and micro heat exchanger; B) Vertical cut through the heat exchanger element and C) Sintered metal fiber catalyst.

tion heat produced in each catalyst layer is directly evacuated in the adjacent upstream heat exchange element. Fig. 7A shows a setup scheme containing a 10-staged bubble column reactor with integrated cooling elements (Fig. 7B).

To keep the compactness of the SBCR, the HEX element has to present a minimal additional reaction volume and at the same time provide a high heat-exchange performance. To meet these requirements, the HEX was designed as vertical micro-slits cut through a circular stainless steel plate of $7 \mathrm{~mm}$ thickness. One element contains 17 slits of $300 \mu \mathrm{m}$ width, cut though the plate at equal distances of $2.4 \mathrm{~mm}$ over the internal reactor cross section. Horizontal cooling water channels of $800 \mu \mathrm{m}$ diam- eter were subsequently drilled through the remaining parallel bars. The result is a stack of cooling tubes of equal length aligned horizontally at a distance of 300 $\mu \mathrm{m}$, forming a micro-heat exchanger stage with cross flow configuration. Fig. 7B shows a vertical cross section through the resulting element geometry of the stainless steel HEX. This design combines low volume with small heat transfer distances.

The performance of the SBCR reactor with integrated micro-heat exchanger was determined for the hydrogenation of 2-methyl-3-butyn-2-ol (MBY) using a high pressure loop setup with the reactor shown in Fig. 7A. The hydrogenation reaction was carried out in the SBCR under different temperatures, $\mathrm{H}_{2}$-pressures and flow 
rates. Particular attention was paid to avoid any mass transfer resistance, and the liquid reactant mixture was always saturated with hydrogen at the corresponding temperature and pressure.

The results are presented in Fig. 8 together with the heat production $\mathrm{q}_{\mathrm{r}}$ calculated as:

$$
q_{r}=r \frac{m_{c a t}}{V_{R}} h\left(-\Delta H_{R}\right)
$$

$$
r=k_{r} C_{H_{2}}=A \exp \left(\frac{-E_{A}}{R T}\right) C_{H_{2}}
$$

where the heat of reaction is $-170 \mathrm{~kJ} \mathrm{~mol}^{-1}$, $\mathrm{m}_{\text {cat }}$ the mass of the catalyst and $\mathrm{V}_{\mathrm{R}}$ the volume of the reactor.

The heat evacuation $q_{e x}$ is calculated for volumetric gas-flow of $\mathrm{Q}_{\mathrm{G}}=1.400 \cdot 10^{-3} \mathrm{~m}^{3}$ $\mathrm{min}^{-1}$ and volumetric liquid-flow of $\mathrm{Q}_{\mathrm{L}}=$ $0.2 \cdot 10^{-3} \mathrm{~m}^{3} \mathrm{~min}^{-1}$, based on a mean temperature difference between reaction mixture and cooling medium of $\Delta T_{m}=15 \mathrm{~K}$. The operating region of the SBCR lies under the horizontal line in Fig. 8 corresponding to $q_{e x}$, where $q_{e x} \geq q_{r}$ and means that the produced reaction heat can be fully evacuated.

The micro-HEX integrated within SBCR with catalytic layers made of Pd/ $\mathrm{ZnO} / \mathrm{SMF}$ showed high specific productivity in a hydrogenation of MBY under isothermal conditions. The attained specific reactor performance was found to be several orders of magnitude above the values reported for conventional multiphase reactors. Adjusting the hydrogen partial pressure can increase the productivity up to the limits governed by the heat transfer performance of the HEX element. Thus, the SBCR with integrated micro-HEX is a suitable design for continuous multiphase hydrogenation leading to significant (two orders of magnitude) process intensification.

\section{Conclusions}

The integrated approach for the design of solid catalysts for process intensification is presented. This approach addresses simultaneously different levels of scale and complexity involved in the development starting from a molecular/nano-scale with the active phase optimization up to a macro-scale of the catalytic reactor design. Therefore, it requires a combination of interdisciplinary competences of chemical reactor and catalytic engineering, synthetic chemistry and surface science, as well as physics and modeling.

The feasibility of this approach has been demonstrated herein via case studies of an industrially relevant selective semi-

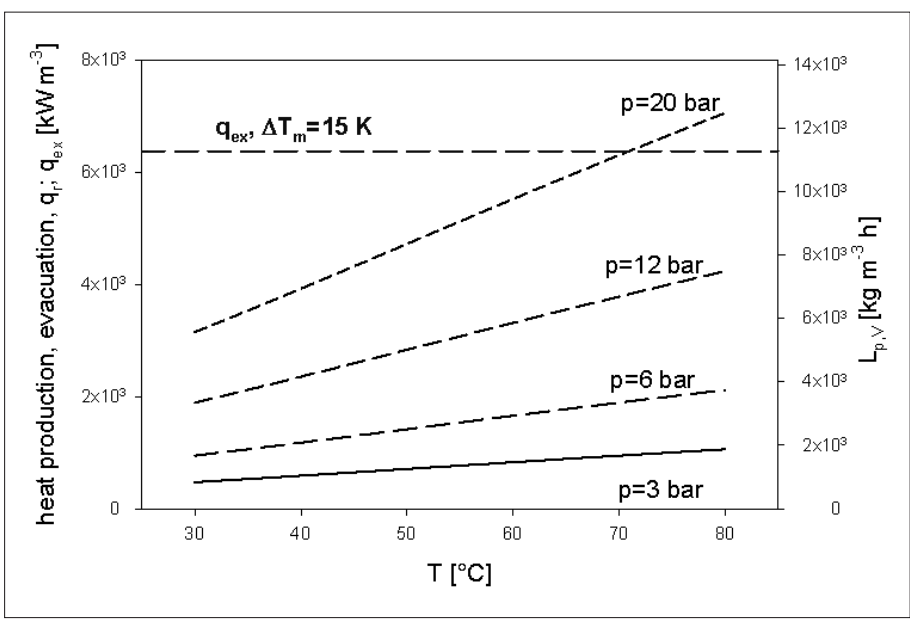

Fig. 8. Specific performance, $L_{p, V}$ of the staged bubble column reactor and heat production as function of temperature and hydrogen pressure.

hydrogenation of 2-methyl-3-butyn-2-ol over Pd-based catalyst structured over multiple levels. The catalysts properties have been 'tuned-on-demand' by mastering $P d$ nanoparticles with controlled size and shape, synthesis of a support which allowed strong anchoring of these NPs without leaching/deactivation, and incorporation of final structured catalyst into a compact reactor with integrated micro-heat exchanger. The performance increased up to a few orders of magnitude as compared to conventional reactor using industrial powder catalyst.

Whatever the future holds for this novel structured catalyst, $[16,17]$ its development has provided a fascinating scientific puzzle and indicated a future direction to implement catalytic processes intensification.

\section{Acknowledgements}

Financial support from the Swiss National Science Foundation (SNSF) and Swiss Commission for Innovations and Technology (CTI) is highly appreciated. LKM thanks Dr. Igor YURANOV for fruitful discussions and help during the preparation of this manuscript.

\section{Received: July 14, 2011}

[1] A. I. Stankiewicz, J. A. Moulijn, Chem. Eng. Progr. 2000, 96, 22.

[2] Cefic, 'Looking at the next decade: innovation and sustainability', August, 2010, http://www. cefic.be.

[3] KPMG International, 'The Future of the European Chemical Industry', August 2010, http://www.cefic.be
[4] European Technology Platform on Sustainable Chemistry, 'Sustainable chemistry: a catalyst for innovation \& growth in Europe'. August 2010, http://www.suschem.org.

[5] A. Cybulski, J. A. Moulijn, 'Structured catalyst and reactors', 2nd ed, 2006, Taylor \& Francis.

[6] L. Kiwi-Minsker, A. Renken, 'Microstructured Reactors', in 'Handbook of Heterogeneous Catalysis', 2008, Wiley-VCH.

[7] L. Kiwi-Minsker, Chimia 2002, 56, 143.

[8] M. Crespo-Quesada, A. Yarulin, M. Jin, Y. Xia L. Kiwi-Minsker, J. Amer. Chem. Soc. 2011 , $133,12787$.

[9] R. Van Hardeveld, F. Hartog, Surf. Sci. 1969, 15, 189.

[10] G. C. Bond, Chem. Soc. Rev. 1991, 20, 441.

[11] M. Che, C. O. Bennett, 'The Influence of Particle Size on the Catalytic Properties of Supported Metals', in 'Advances in Catalysis', 1989, Academic Press. pp 55-172.

[12] T. O. Omarkulov, Z. Mukataev, S. V. Goncharova, D. V. Sokol'skii, Rus. J. Phys. Chem. 1985, 59, 137.

[13] M. Crespo-Quesada, M. Grasemann, N Semagina, A. Renken, L. Kiwi-Minsker, Catal. Today 2009, 147, 247.

[14] N. Semagina, M. Grasemann, N. Xanthopoulos, A. Renken, L. Kiwi-Minsker, J. Catal. 2007, $251,213$.

[15] M. Grasemann, A. Renken, M. Kashid, L. KiwiMinsker, Chem. Eng. Sci. 2010, 65, 364.

[16] W. Bonrath, L. Kiwi-Minsker, A. Renken, N. Semagina, WO2008101602-A2, WO2008101602-A3, EP2112955-A2, CN101616736-A, IN200905309-P1, 2008, N01244.

[17] W. Bonrath, M. Grasemann, A. Renken, N. Semagina, L. Kiwi-Minsker, WO2008101603-A2, WO2008101603-A3, EP2125199-A2, CN101616733-A, IN200905323-P1, 2008, M80191. 